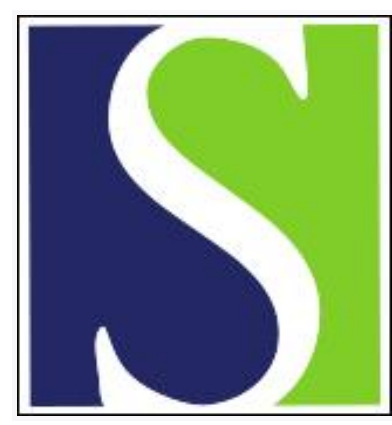

Scand J Work Environ Health 2005;31(3):212-217

https://doi.org/10.5271/sjweh.871

Issue date: Jun 2005

\title{
Reproductive outcomes among hairdressers
}

by Rylander L, Källén B

Affiliation: Department of Occupational and Environmental Medicine, Institute of Laboratory Medicine, University Hospital, SE-221 85 Lund, Sweden. lars.rylander@ymed.lu.se

The following articles refer to this text: 2013;39(3):302-309; 2020;46(4):417-428

Key terms: birthweight; hairdresser; malformation; preterm birth; reproductive outcome; stillbirth

This article in PubMed: www.ncbi.nlm.nih.gov/pubmed/15999573 


\title{
Reproductive outcomes among hairdressers
}

\author{
by Lars Rylander, DrMedSc, ${ }^{1}$ Bengt Källén, $M D^{2}$
}

\begin{abstract}
Rylander L, Källén B. Reproductive outcomes among hairdressers. Scand J Work Environ Health 2005;31(3): 212-217.
\end{abstract}

Objectives The present study aimed at examining the possible risk of working as a hairdresser during pregnancy in relation to reproductive outcomes.

Methods The Swedish Medical Birth Register, which includes almost every infant born in Sweden, has, since 1983, collected information prospectively about occupation in early pregnancy. This information is given at the first visit to a prenatal center. During the period 1983-2001, 12046 infants were born to female hairdressers working either full- or part-time during early pregnancy. For comparison, all other deliveries during the same period were used in which the mother had worked either part-time or full-time.

Results The full-time hairdressers more often had intrauterine growth-retarded infants (ie, small for gestational age) as compared with referents with a corresponding worktime [adjusted odds ratio (OR) $1.20,95 \%$ confidence interval (95\% CI) 1.06-1.36]. The pattern was similar for part-time hairdressers (adjusted OR 1.16, 95\% 0.931.46). The fraction of malformations did not differ from those among the referents. The gender ratio for the infants of hairdressers was similar to that for the overall Swedish population.

Conclusions The findings concerning infants small for their gestational age in the present study is in accordance with previous findings. The reason for these findings remains unknown. Studies with more-specific exposure information during pregnancy are needed.

Key terms birthweight; malformation; preterm birth; stillbirth.

In Sweden more than 15000 women work as a hairdresser. They constitute a major occupational group exposed to a wide range of products with potential reproductive toxicity.

Their work involves exposure to a variety of chemical agents as a result of the use of hair products like shampoos, permanent-wave solutions, hair dyes, and hair sprays (1). For several agents reproductive toxicity has been reported in animal studies, but no or few human data are available. Examples are selenium sulfide, which is used in antidandruff shampoos $(2,3)$, some dye formulations containing agents such as 2,5-diaminotoluene and phenylenediamines (4-7), and dibuthylphthalate, which is used in hair spray (8). In the animal studies high doses have been administered, whereas the concentrations of these agents in hairdressing salons are relatively low (1). Reproductive disorders in humans have been described in relation to high exposures to organic solvents $(9,10)$, nitrosamines $(11)$, formaldehyde $(3,12)$, and hexachlorophene (13). Again, the levels of these agents in hairdressing salons are relatively low. On the other hand, hairdressers are exposed to a mixture of these agents, and it is therefore difficult to make direct toxicologic estimates based on data on single agents.

In addition to exposure to chemical agents, work as a hairdresser also consists of prolonged bending and standing positions (14-16) and work-related stress (1720), which may be unfavorable for reproduction.

There are only few epidemiologic studies on reproductive risks among hairdressers. A questionnaire-based cohort study from The Netherlands indicated an increased occurrence of infants with a low birthweight and infants with malformations (21). However, the numbers, especially for malformations, were very low, and the increased risk estimates were far from statistically significant. Another cohort study that consisted of women certified at the major hairdressing schools in Sweden also showed an increased frequency of low birthweight and major malformations among infants born to these

1 Department of Occupational and Environmental Medicine, Institute of Laboratory Medicine, University of Lund, Lund, Sweden.

2 Tornblad Institutet, University of Lund, Lund, Sweden.

Correspondence to: Dr Lars Rylander, Department of Occupational and Environmental Medicine, Institute of Laboratory Medicine, University Hospital, SE-221 85 Lund, Sweden. [E-mail: lars.rylander@ymed.lu.se] 
women (22), but for a large proportion it was not known if they actually worked as a hairdresser during pregnancy.

In addition to these cohort studies, a few studies have indicated increased risks for more-specific malformations among hairdressers (23-25). The pattern is, however, inconclusive and a need for more studies exists.

The aim of our study was to investigate the risk of working as a hairdresser in relation to reproductive outcome, by using information collected prospectively about occupation in early pregnancy.

\section{Study population and methods}

\section{Hairdressers}

The Swedish Medical Birth Register (MBR) includes almost every (coverage about 98-99\%) infant born in Sweden since 1973 (26, 27). The MBR is based on copies of medical record forms from maternity health care, delivery, and pediatric examinations of newborn. Since 1983, the MBR has contained information about occupation in early pregnancy, recorded at the first visit to a prenatal health center, usually around week 10-12. This occupational information is a verbal description and is not coded in the MBR. In our study, we used free-text searching of the MBR to identify records during the period 1983-2001 on deliveries in which the occupational description included a syllable that is usually part of the occupation title as a hairdresser in Swedish ("FRIS"). This search resulted in 388 different occupational descriptions. After a careful review, 111 descriptions obviously did not mean "working as a hairdresser" and were therefore excluded. For 14492 deliveries, the occupational descriptions included any of the other 277 alternatives. The MBR also includes information about worktime (two alternatives: full-time or parttime). In our study, we only included deliveries for which this information was known. Thus we ended up with 8384 women who had given birth to 12046 infants in 11901 deliveries (table 1). Among them, 5251 had one delivery during the study period, 2782 had two deliveries, 319 had three, 31 had four, and 1 had five.

\section{Referents}

For comparison, we used all other deliveries during the period 1983-2001 when the mother had stated that she worked part-time or full-time, which corresponded to $66 \%$ of all deliveries. This group included 775840 deliveries for which the mother had worked full-time and 500222 deliveries for which the mother had worked part-time.

\section{Characteristics of the hairdresser cohort}

The background characteristics for the cohort of hairdressers are shown in table 1. Among the full-time workers, hairdressers more often had their infants between the ages of 20 and 24 years than the reference women [odds ratio (OR) adjusted for year of birth, parity, maternal country of birth, and smoking 1.41, 95\% confidence interval (95\% CI) 1.34-1.49]. Among the part-time workers, the hairdressers had their infants more often between the ages of 25 and 29 years than the reference women (OR adjusted for year of birth, parity, maternal country of birth, and smoking 1.27, 95\% CI 1.20-1.35). It was more common with parity one among the full-time hairdressers as compared with the referents working full-time (OR adjusted for year of birth, maternal age, maternal country of birth, and smoking $1.45,95 \%$ CI 1.37-1.53), whereas it was more common with parity two among the part-time hairdressers than among the referents who worked part-time (OR

Table 1. Background characteristics of a cohort of hairdressers in Sweden.

\begin{tabular}{|c|c|c|c|c|c|c|}
\hline & \multicolumn{4}{|c|}{ Worktime } & \multicolumn{2}{|c|}{ Allc } \\
\hline & \multicolumn{2}{|c|}{ Full-time ${ }^{\mathrm{a}}$} & \multicolumn{2}{|c|}{ Part-time ${ }^{b}$} & \multirow[b]{2}{*}{$\mathrm{N}$} & \multirow[b]{2}{*}{$\%$} \\
\hline & $\mathrm{N}$ & $\%$ & $\mathrm{~N}$ & $\%$ & & \\
\hline \multicolumn{7}{|l|}{ Calendar year of birth } \\
\hline 1983-1987 & 1550 & 21 & 1180 & 26 & 2730 & 23 \\
\hline 1988-1992 & 2189 & 29 & 1294 & 29 & 3483 & 29 \\
\hline 1993-1997 & 2276 & 30 & 1224 & 27 & 3500 & 29 \\
\hline 1998-2001 & 1543 & 20 & 790 & 18 & 2333 & 19 \\
\hline \multicolumn{7}{|l|}{ Maternal age } \\
\hline $15-19$ & 112 & 1 & 17 & 0 & 129 & 1 \\
\hline $20-24$ & 2122 & 28 & 663 & 15 & 2785 & 23 \\
\hline $25-29$ & 3147 & 42 & 1959 & 44 & 5106 & 42 \\
\hline $30-34$ & 1564 & 21 & 1397 & 31 & 2961 & 25 \\
\hline$\geq 35$ & 613 & 8 & 452 & 10 & 1065 & 9 \\
\hline \multicolumn{7}{|l|}{ Parity } \\
\hline 1 & 5354 & 71 & 739 & 16 & 6093 & 51 \\
\hline 2 & 1569 & 21 & 2780 & 62 & 4349 & 36 \\
\hline$\geq 3$ & 635 & 8 & 969 & 22 & 1604 & 13 \\
\hline \multicolumn{7}{|c|}{ Smoking habits in early pregnancy } \\
\hline 0 cigarettes/day & 5560 & 74 & 3449 & 77 & 9009 & 75 \\
\hline 1-9 cigarettes/day & 1170 & 15 & 629 & 14 & 1799 & 15 \\
\hline$\geq 10$ cigarettes/day & 539 & 7 & 264 & 6 & 803 & 7 \\
\hline Unknown & 289 & 4 & 146 & 3 & 435 & 4 \\
\hline \multicolumn{7}{|c|}{ Maternal country of birth } \\
\hline Sweden & 6660 & 88 & 4151 & 92 & 10811 & 90 \\
\hline Other & 898 & 12 & 337 & 8 & 1235 & 10 \\
\hline \multicolumn{7}{|c|}{ Maternal body mass index 1992-2001 } \\
\hline$<19.8$ kg/m² & 464 & 8 & 76 & 10 & 540 & 8 \\
\hline $19.8-24.9 \mathrm{~kg} / \mathrm{m}^{2}$ & 3291 & 57 & 419 & 55 & 3710 & 57 \\
\hline $25-29.9 \mathrm{~kg} / \mathrm{m}^{2}$ & 1018 & 18 & 126 & 17 & 1144 & 18 \\
\hline$\geq 30 \mathrm{~kg} / \mathrm{m}^{2}$ & 268 & 5 & 28 & 4 & 296 & 5 \\
\hline Unknown & 719 & 13 & 111 & 15 & 830 & 13 \\
\hline
\end{tabular}

a 7558 infants were born; 7465 deliveries took place.

b 4488 infants were born; 4436 deliveries took place.

c 12046 infants were born; 11901 deliveries took place. 
adjusted for year of birth, maternal age, maternal country of birth, and smoking $1.59,95 \%$ CI 1.50-1.70). The full-time hairdressers smoked ( $\geq 10$ cigarettes/day) somewhat more than the referents working full-time (OR adjusted for year of birth, maternal age, maternal country of birth, and parity $1.13,95 \%$ CI 1.03-1.24), whereas no difference was observed between the hairdressers and referents working part-time. The full-time hairdressers were born outside Sweden more often than the referents working full-time (OR adjusted for year of birth, maternal age, parity, and smoking 1.27, 95\% CI 1.18-1.36). No difference was observed between the part-time hairdressers and their referents with respect to country of birth. The body mass index (BMI) of the women could only be studied for the period 19922001 - there was a slight excess among the hairdressers with a normal BMI $\left(19.8-24.9 \mathrm{~kg} / \mathrm{m}^{2}\right)$.

\section{Outcome variables}

The reproductive outcomes studied were gender ratio, mean birthweight, low birthweight (low birthweight $<2.5 \mathrm{~kg}$ ), preterm birth ( $<37$ weeks), small for gestational age (28), stillbirth, early neonatal death (END, $<7$ days of age), all malformations, and so-called "weeded" malformations (a register term which excludes some minor malformations, such as preauricular appendices, undescended testicles, unstable hip, and nevus). The analysis of malformations was restricted to such cases registered in the MBR. Malformed fetuses, aborted after fetal diagnosis, were not included.

\section{Statistical methods}

Estimates of risks were made using Mantel-Haenszel procedures and expressed as odds ratios (OR) with $95 \%$ confidence intervals $(95 \% \mathrm{CI})$ determined with Miettinen's test-based method (29). Adjustments were made for year of birth (1-year classes), maternal age (5-year classes), parity $(1,2,3, \geq 4)$, and maternal smoking in early pregnancy (unknown, none, $<10, \geq 10$ cigarettes/day). When the expected number of outcomes was small, a risk ratio was used instead as a quotient between the observed and expected number, the latter estimated from the population and with adjustments as presented earlier in the text. Then the $95 \%$ confidence interval was based on exact Poisson distributions.

\section{Results}

\section{Birthweight, low birthweight, preterm birth and small for gestational age}

The mean birthweight was significantly lower $(\mathrm{P}<0.01)$ for the singleton infants of full-time hairdressers [3459 (SD 545) grams] than for the singleton infants of the referents working full-time [3513 (SD 563) grams,]. The difference was somewhat smaller (although significant, $\mathrm{P}<0.01$ ), when the singleton infants of part-time hairdressers were compared with the singleton infants of the referents working part-time (mean birthweight 3556 and 3583 grams, respectively). Among the full-time workers, the hairdressers more often had significantly intrauterine growth-retarded singleton infants (small for gestational age) than the referents (adjusted OR 1.20, 95\% CI 1.06-1.36)(table 2). Among the part-time workers, the hairdressers more often had preterm singleton births than the referents had (adjusted OR 1.20, 95\% 1.04-1.37). Furthermore, the part-time hairdressers tended to have singleton infants with low birthweight and small for gestational age more often than the referents.

The adjusted odds ratio for low birthweight in the earlier period (1983-1992) was 1.11 (95\% CI 0.93$1.31)$, as it was also [1.11 (95\% CI 0.93-1.29)] for the

Table 2. Risk of having an infant with a low birthweight $(<2.5 \mathrm{~kg})$, preterm birth $(<37$ weeks), or that was small for its gestational age or had a major malformation in a cohort of Swedish women who worked as a hairdresser during early pregnancy as compared with women from the general population who worked in other occupations during early pregnancy. ( $\mathrm{R}=$ odds ratio, $95 \% \mathrm{Cl}=95 \% \mathrm{confidence}$ interval, LBW = low birthweight, SGA = small for gestational age)

\begin{tabular}{|c|c|c|c|c|c|c|c|c|c|c|c|c|}
\hline & \multicolumn{8}{|c|}{ Worktime } & \multicolumn{4}{|c|}{ All } \\
\hline & \multicolumn{4}{|c|}{ Full-time } & \multicolumn{4}{|c|}{ Part-time } & \multirow[b]{2}{*}{$\begin{array}{l}\text { Crude } \\
\text { OR }\end{array}$} & \multirow[b]{2}{*}{$95 \% \mathrm{Cl}$} & \multirow{2}{*}{\multicolumn{2}{|c|}{$\begin{array}{l}\text { Adjusted a } 95 \% \mathrm{Cl} \\
\text { OR }\end{array}$}} \\
\hline & $\begin{array}{l}\text { Crude } \\
\text { OR }\end{array}$ & $95 \% \mathrm{Cl}$ & $\begin{array}{c}\text { Adjusted } \\
\text { OR }\end{array}$ & d a $95 \% \mathrm{Cl}$ & $\begin{array}{c}\text { Crude } \\
\text { OR }\end{array}$ & $95 \% \mathrm{Cl}$ & $\begin{array}{c}\text { Adjusted } \\
\text { OR }\end{array}$ & a $95 \% \mathrm{Cl}$ & & & & \\
\hline $\mathrm{LBW}^{\mathrm{b}}$ & 1.10 & $0.98-1.23$ & 1.06 & $0.94-1.19$ & 1.11 & $0.93-1.31$ & 1.18 & $0.99-1.40$ & 1.11 & $1.00-1.21$ & 1.10 & $0.99-1.21$ \\
\hline Preterm birth ${ }^{b}$ & 1.00 & $0.91-1.11$ & 0.98 & $0.88-1.08$ & 1.12 & $0.98-1.28$ & 1.20 & $1.04-1.37$ & 1.05 & $0.96-1.13$ & 1.05 & $0.96-1.14$ \\
\hline$S G A$ & 1.30 & $1.15-1.47$ & 1.20 & $1.06-1.36$ & 1.05 & $0.84-1.31$ & 1.16 & $0.93-1.46$ & 1.24 & $1.12-1.38$ & 1.19 & $1.07-1.33$ \\
\hline "Weeded" malformation c & 1.01 & $0.87-1.17$ & 1.01 & $0.87-1.18$ & 0.94 & $0.77-1.15$ & 0.96 & $0.79-1.18$ & 0.98 & $0.87-1.11$ & 0.99 & $0.88-1.12$ \\
\hline
\end{tabular}

adjusted for year of birth, maternal age, parity, and maternal smoking.

b Multiple births excluded.

c For a definition, see the methods section. 
Table 3. Delivery outcomes among 12046 infants born to 8384 hairdressers and 1280791 infants born to reference women in Sweden during the period 1983-2001.

\begin{tabular}{|c|c|c|c|c|c|c|c|c|}
\hline & \multicolumn{4}{|c|}{ Hairdressers } & \multicolumn{4}{|c|}{ Referents } \\
\hline & \multicolumn{2}{|c|}{ Full-time } & \multicolumn{2}{|c|}{ Part-time } & \multicolumn{2}{|c|}{ Full-time } & \multicolumn{2}{|c|}{ Part-time } \\
\hline & $\mathrm{N}$ & $\%$ & $\mathrm{~N}$ & $\%$ & $\mathrm{~N}$ & $\%$ & $\mathrm{~N}$ & $\%$ \\
\hline Low birthweight $(<2.5 \mathrm{~kg})^{\text {a }}$ & 291 & 4.0 & 137 & 3.1 & 27339 & 3.6 & 13903 & 2.8 \\
\hline Preterm birth $(<37 \text { weeks })^{\text {a }}$ & 399 & 5.4 & 221 & 5.0 & 40859 & 5.4 & 22175 & 4.5 \\
\hline Small for gestational age ${ }^{a}$ & 271 & 3.7 & 81 & 1.9 & 21587 & 2.9 & 8630 & 1.8 \\
\hline Stillbirths & 21 & 0.3 & 11 & 0.2 & 2699 & 0.4 & 1587 & 0.3 \\
\hline Early neonatal deaths ( $<7$ days) & 17 & 0.1 & 5 & 0.1 & 1752 & 0.2 & 1102 & 0.2 \\
\hline All malformations & 312 & 4.1 & 147 & 3.3 & 31083 & 4.0 & 19448 & 3.9 \\
\hline "Weeded" malformations b & 178 & 2.4 & 98 & 2.2 & 18219 & 2.3 & 11610 & 2.3 \\
\hline
\end{tabular}

a Multiple births excluded.

b For a definition, see the methods section.

later period (1993-2001). For small for gestational age the odds ratio was 1.23 (95\% CI 1.06-1.44) and 1.09 (95\% CI 0.93-1.29), respectively.

\section{Stillbirth and early neonatal death}

Among the infants of all the hairdressers, $0.3 \%$ was stillborn and $0.1 \%$ had an early neonatal death (table 3 ). These events were rare also among the reference infants, and because of the small numbers no comparisons were made.

\section{Malformations}

The fraction of weeded malformations was $2.4 \%$. Among the infants of the full-time hairdressers, $2.4 \%$ had a "weeded" malformation, and for the infants of the part-time hairdressers this proportion was $2.2 \%$ (table 3 ). None of these rates differed from those of the infants of the referents (table 2). Table 4 shows the observed and expected numbers of some groups of relatively major malformations. Even though some of the risk ratios were around 2, the confidence intervals were large and did not exclude unity.

\section{Gender ratio}

The fraction of boys among the infants born by hairdressers was $51.1 \%$ (95\% CI 50.2-52.0); this proportion is very similar to that of the referents (ie, $51.5 \%$ ).

\section{Discussion}

The main finding of our study was an increased risk of having an infant small for its gestational age among women who worked as a hairdresser in early pregnancy as compared with women within other occupations.
Table 4. Observed $(0)$ and expected (E) (adjusted for year of birth, maternal age, parity, and smoking) of some major malformations. The risk ratio ( $R R=$ observed to expected numbers) with $95 \%$ confidence intervals $(95 \% \mathrm{CI})$ based on Poisson distributions.

\begin{tabular}{lrrrr}
\hline Congenital malformation & 0 & E & RR & $95 \% \mathrm{Cl}$ \\
\hline Spina bifida & 5 & 4.1 & 1.2 & $0.5-2.9$ \\
Orofacial cleft & 16 & 19.2 & 0.8 & $0.5-1.4$ \\
Cardiovascular defect $^{\mathrm{a}}$ & 90 & 95.4 & 0.9 & $0.8-1.2$ \\
Esophageal atresia $_{\text {Small gut atresia }}$ & 5 & 2.6 & 1.9 & $0.8-4.6$ \\
Anal atresia & 4 & 1.8 & 2.3 & $0.9-5.9$ \\
Any alimentary tract atresia & 1 & 2.8 & 0.4 & $0.1-2.4$ \\
Limb reduction defect & 10 & 6.9 & 1.5 & $0.8-2.7$ \\
Abdominal wall defect & 6 & 4.6 & 1.3 & $0.6-3.0$ \\
Hypospadias & 3 & 1.4 & 2.1 & $0.7-6.4$ \\
Kidney/urinary tract malformation & 8 & 14.0 & 0.6 & $0.3-1.1$ \\
\hline
\end{tabular}

a Excluding patent ductus and single umbilical artery.

There was, however, no indication of an increased risk of having an infant with major malformations among the hairdressers.

About 25\% of the hairdressers in our study were also included in a former study of Swedish hairdressers (22). When the analyses in our study were restricted to the hairdressers who were not included in the former study, the results did not change more than marginally.

The Swedish MBR includes almost every infant born in Sweden since 1973 (26, 27). The outcome variables in our study were based on data from the MBR. The quality of birthweight has been judged to be good, whereas it is more difficult to get a good estimate of gestational length. For the larger part of the study period, information on gestational length was based on the results of a second trimester ultrasound. It is, however, reasonable to believe that the estimates of gestational length were probably affected by nondifferential errors. Such misclassification would tend to produce bias toward the null $(30,31)$. 
A major strength of our study was that the occupational information was gathered prospectively. The information was collected in early pregnancy, and, therefore, it was not biased by the pregnancy outcome. In addition, the MBR contained information about workhours (full- or part-time). On the other hand, we had no information about occupation in late pregnancy. It is reasonable to believe that some of the hairdressers stopped working as a hairdresser during late pregnancy. If working as a hairdresser in late pregnancy had a negative effect on the reproductive outcome, we would then have underestimated the true risk. The way we searched the register probably did not identify all women working as a hairdresser during pregnancy. However, if it is born in mind that the hairdressers represented $<1 \%$ of all women giving birth in the population, the inclusion of some hairdressers among the referents was of little importance to the effect estimates in our study.

It is, of course, important to take possible confounders into consideration. But the significant increased risk of having an infant small for its gestational age among the hairdressers was present also when infant year of birth, maternal age, parity, and smoking were taken into account. We therefore do not believe that confounding regarding these factors was of major concern in our study. We did not include maternal country of birth or BMI in the models. The full-time hairdressers were born outside Sweden than more often the referents who worked full-time. When separate analyses were performed restricted to women born in Sweden, the effect estimates did not change more than marginally (data not shown). Unfortunately data on BMI were only available for about $50 \%$ of the women, and therefore we did not adjust for BMI in the models. However, the available data did indicate that the hairdressers had a normal BMI more often than the referents, and, accordingly, the impact of excluding BMI from the models was probably of minor importance. Hairdressers are, by definition, a group with a very similar educational level. Educational level was not available in the MBR for the whole period. However, it has been shown in studies among populations in Sweden that the effect of educational level was almost eliminated when smoking was taken into account. Other undetected confounders may, however, exist.

In the analyses, the birth rather than the mother represents the unit of observation. The effect estimates were, however, not influenced more than marginally if we only included parity one in the analyses (data not shown).

The findings for low birthweight and small for gestational age in our study are partly in agreement with previous findings $(21,22)$. In the study from The Netherlands, the authors stated that the risk had decreased over time, and they thought that this decrease may be a result of exchanging the toxic agents in the beauty salons for less hazardous ones (21). In our study, we did not find any significant time trends. In a former study among hairdressers from Sweden many hours of work per week and many treatments of permanent waving and shampooing per week tended to be negatively associated with low birthweight (22). Moreover, many treatments of permanent waving and spraying per week tended to be negatively associated with infants being small for their gestational age. The reason hairdressers in our study had increased risks of having an infant with a low birthweight or small for its gestational age remains unknown and calls for studies with more-specific exposure information during pregnancy.

An increased risk for preterm birth was observed only for the part-time hairdressers. The earlier study among hairdressers in Sweden indicated no significant association $(\mathrm{P}=0.30)$ between hours of work per week and preterm birth (22). Our prior hypothesis was a doseresponse dependent relationship (ie, a more pronounced negative effect among the full-time hairdressers). Thus the observed effect among the part-time hairdressers observed in our study remains unclear and may be due to chance.

Previous studies had indicated increased risks of hairdressers having an infant with a major malformation, such as oral clefts and hypospadias (21-24). The pattern in the previous studies is not, however, consistent. Our study, which is the largest one, does provide any support for the hypothesized association between working as a hairdresser and having these specific malformations. It should be remembered that the actual exposure situation may well vary between different populations.

\section{Acknowledgments}

We thank the National Board of Health for access to the register files. The study was supported by grants from the Swedish Council for Work Life Research (LR) and from $\mathrm{K}$ and $\mathrm{A}$ Wallenberg Foundation (BK).

\section{References}

1. Kersemaekers WM, Roeleveld N, Zielhuis GA. Reproductive disorders due to chemical exposure among hairdressers [review]. Scand J Work Environ Health 1995;21(5):325-34.

2. Amdur M, Doull J, Klaassen C. Casaret and Doull's toxicology—the basic science of poisons. New York (NY): Pergamon Press; 1993.

3. Schardein J. Chemically induced birth defects. New York, Basel: Marcel Dekker Inc; 1985. 
4. Inouye M, Murakami U. Teratogenicity of 2,5-diaminotoluene, a hair-dye constituent, in mice. Food Cosmet Toxicol 1977;15(5):447-51.

5. Marks TA, Gupta BN, Ledoux TA, Staples RE. Teratogenic evaluation of 2-nitro-p-phenylenediamine, 4-nitro-o-phenylenediamine, and 2,5-toluenediamine sulfate in the mouse. Teratology 1981;24(3):253-65.

6. Picciano JC, Morris WE, Wolf BA. Evaluation of the teratogenic potential of the oxidative dyes 6-chloro-4-nitro-2aminophenol and o-chloro-p-phenylenediamine. Food Chem Toxicol 1984;22(2):147-9.

7. Burnett CM, Goldenthal EI. Multigeneration reproduction and carcinogenicity studies in Sprague-Dawley rats exposed topically to oxidative hair-colouring formulations containing pphenylenediamine and other aromatic amines. Food Chem Toxicol 1988;26(5):467-74.

8. Commission of the European Communities (CEC). Reproductive toxicity: the toxicology of chemicals, series two. Luxembourg, Edinburgh: Office for Official Publications of the European Communities; 1993.

9. Huel G, Mergler D, Bowler R. Evidence for adverse reproductive outcomes among women microelectronic assembly workers. Br J Ind Med 1990;47(6):400-4.

10. Lipscomb JA, Fenster L, Wrensch M, Shusterman D, Swan S. Pregnancy outcomes in women potentially exposed to occupational solvents and women working in the electronics industry. J Occup Med 1991;33(5):597-604.

11. Preston-Martin S, Yu MC, Benton B, Henderson BE. N-Nitroso compounds and childhood brain tumors: a case-control study. Cancer Res 1982;42(12):5240-5.

12. Barlow S, Sullivan F. Reproductive hazards of industrial chemicals: an evaluation of animal and human data. London: Academic Press; 1982.

13. Roeleveld N. Mental retardation and parental occupation: an explorative epidemiologic study. Nijmegen (The Netherlands): University of Nijmegen; 1991.

14. McDonald AD, McDonald JC, Armstrong B, Cherry NM, Nolin AD, Robert D. Prematurity and work in pregnancy. Br J Ind Med 1988;45(1):56-62.

15. Henriksen TB, Hedegaard M, Secher NJ, Wilcox AJ. Standing at work and preterm delivery. Br J Obstet Gynaecol 1995;102(3):198-206.

16. Mozurkewich EL, Luke B, Avni M, Wolf FM. Working conditions and adverse pregnancy outcome: a meta-analysis. Obstet Gynecol 2000;95(4):623-35.

17. Hjollund NH, Jensen TK, Bonde JP, Henriksen TB, Andersson AM, Kolstad HA, et al. Distress and reduced fertility: a follow-up study of first-pregnancy planners. Fertil Steril 1999;72(1):47-53.

18. Fenster L, Waller K, Chen J, Hubbard AE, Windham GC, Elkin E, et al. Psychological stress in the workplace and menstrual function. Am J Epidemiol 1999;149(2):127-34.

19. Hedegaard M. Life style, work and stress, and pregnancy outcome. Curr Opin Obstet Gynecol 1999;11(6):553-6.

20. Hatch MC, Figa-Talamanca I, Salerno S. Work stress and menstrual patterns among American and Italian nurses. Scand J Work Environ Health 1999;25(2):144-50.

21. Kersemaekers WM, Roeleveld N, Zielhuis GA. Reproductive disorders among hairdressers. Epidemiology 1997;8(4):396401.

22. Rylander L, Axmon A, Toren K, Albin M. Reproductive outcome among female hairdressers. Occup Environ Med 2002;59(8):517-22.

23. Lorente C, Cordier S, Bergeret A, De Walle H, Goujard J, Ayme S, et al. Maternal occupational risk factors for oral clefts. Scand J Work Environ Health 2000;26(2):137-45.

24. Vrijheid M, Armstrong B, Dolk H, van Tongeren M, Botting B. Risk of hypospadias in relation to maternal occupational exposure to potential endocrine disrupting chemicals. Occup Environ Med 2003;60(8):543-50.

25. Martines-Frias M, Bermejo E, Rodriguez-Pinilla E, Prieto L. Case-control study of occupation as hairdresser during pregnancy and congenital defects. Environ Epidemiol Toxicol 2000;2:20-23.

26. Cnattingius S, Ericson A, Gunnarskog J, Kallen B. A quality study of a medical birth registry. Scand J Soc Med 1990;18(2):143-8.

27. The Swedish Medical Birth Register-a summary of contents and quality [homepage on the internet]. Stockholm: Centre of Epidemiology, The National Board of Health and Welfare; 2002. Available from: http://www.sos.se/fulltext/112/2003112-3/2003-112-3.pdf (accessed July 2004)

28. Kallen B. A birth weight for gestational age standard based on data in the Swedish Medical Birth Registry, 1985-1989. Eur J Epidemiol 1995;11(5):601-6.

29. Miettinen O. Simple interval estimation of risk ratio. Am J Epidemiol 1974;100:515-6.

30. Wacholder S, Hartge P, Lubin JH, Dosemeci M. Non-differential misclassification and bias towards the null: a clarification. Occup Environ Med 1995;52(8):557-8.

31. Rothman K, Greenland S. Modern Epidemiology. Philadelphia (PA): Lippincott-Raven; 1998.

Received for publication: 10 September 2004 